\title{
Electrical and Thermal Characteristics of Pb-Free Sn-Zn Alloys for an AC-Low Voltage Fuse Element
}

\author{
Kazuhiro Matsugi ${ }^{1}$, Gen Sasaki ${ }^{1}$, Osamu Yanagisawa ${ }^{1}$, Yasuo Kumagai ${ }^{2}$ and Koji Fujii ${ }^{2}$ \\ ${ }^{1}$ Department of Mechanical Materials Engineering, Hiroshima University, Higashi-Hiroshima 739-8527, Japan \\ ${ }^{2}$ The Chugoku Electric Power Co. Inc., Hiroshima 730-8701, Japan
}

The temperature dependence of specific resistivity and thermal conductivity for some $\mathrm{Sn}$ - $\mathrm{Zn}$ alloys was measured to use their values in electrical and thermal calculations on the basis of Ohm's and Fourier's laws, in order to obtain the temperature-distribution in lead-free fuse elements of electric power line. The interaction between microstructures and their properties was also investigated in Sn-Zn alloys. Specific resistivity and thermal conductivity could be estimated as a function of temperature and alloy composition in the compositional ranges classified from the standpoint of continuity or non-continuity of constituent phases such as primary Zn, Sn-solid solution and eutectic in microstructures of $\mathrm{Sn}-1$ to $100 \mathrm{Zn}$ alloys. In the proposed estimations, not only volume fraction of $\mathrm{Zn}$ and $\mathrm{Sn}$-solid solution phases but morphologies of both phases were considered in Sn-Zn alloys. [doi:10.2320/matertrans.48.1105]

(Received January 23, 2007; Accepted March 1, 2007; Published April 25, 2007)

Keywords: specific resistivity, thermal conductivity, lead-free tin-zinc alloys, fuse element, environmentally friendly materials, two phase materials, substitute materials

\section{Introduction}

Lead and its alloys or compounds are considered environmental hazards because of lead's toxicity therefore many countries are going to ban their use. ${ }^{1,2)}$ The practical $\mathrm{Pb}-\mathrm{Sn}$ alloys used as solders in electrical and electronic industries are classified into two groups ( $\mathrm{Pb}-5$ mass $\% \mathrm{Sn}$ and $\mathrm{Pb}-60$ mass $\% \mathrm{Sn}$ ) by their melting temperatures. The $\mathrm{Pb}-60 \mathrm{Sn}$ alloy has been also used as AC-low voltage fuse elements in electric power line. ${ }^{3,4)}$ Due to the world-wide legislative requirements, ${ }^{5,6)}$ it is important to develop viable alternative $\mathrm{Pb}$-free alloys for AC-fuse elements used in electric power line. The main requirements for alternative fusible alloys are:

(1) Low melting point: The melting points should be comparable to practical $\mathrm{Sn}-\mathrm{Pb}$ system alloys.

(2) Availability: There should be adequate supplies or reserves available of candidate metals.

(3) Ability of manufacture: The production of raw materials should not be difficult.

The Sn-9Zn alloy has been investigated in our previous study as a Pb-free alloy for low-voltage fuse elements, except for the points of its performance in a break at high value (3000A) in electric current, weather proof and wettability on copper. ${ }^{3,4,7)}$ In contrast, since an eutectic point $(471 \mathrm{~K})$ of Sn$\mathrm{Zn}$ system alloys is similar to that $(456 \mathrm{~K})$ of the practically used $\mathrm{Pb}-60 \mathrm{Sn}$, it has been also considered by other investigators as a candidate alloy system for a lead-free solder material..$^{8,9)}$ The $\mathrm{Sn}-\mathrm{Zn}$ eutectic system which is basically classified as an anomalous eutectic alloy, has a broken-lamellar type eutectic structure. ${ }^{10)}$ The faceting lamellas are $\mathrm{Zn}$ and the nonfaceting face is the $\mathrm{Sn}$ matrix. Under rapid cooling conditions, the lamellar $\mathrm{Zn}$ becomes fibrous, ${ }^{10,11)}$ which means the sensitivity to solidifying conditions. It is considered that electrical and thermal conductivity of $\mathrm{Sn}-\mathrm{Zn}$ eutectic system alloys are difficult to be estimated using Maxwell ${ }^{12)}$ and Landauer $^{13)}$ models, because those properties are directly influenced by morphology of each phase in them.
It is important in the shape-design of fuse elements that temperature distributions in the fuse element-connectorelectric wire system, are exactly known in some conditions evaluating the main requirements ${ }^{7)}$ (period showing melt or un-melt down and temperature increment at fixed current flow conditions) for AC-low voltage fuse elements. The heterogeneity in potential and temperature was predicted by simulations for fuse elements at higher temperatures. ${ }^{7)}$ The temperature dependence of specific resistivity, thermal conductivity and specific heat or the temperature conductivity in $\mathrm{Sn}-\mathrm{Zn}$ system alloys, must measured exactly for optimization of shape and alloy-composition in fuse elements, because computer simulation consists of electrical and thermal calculations on the basis of Ohm's and Fourier's laws, respectively. Furthermore, the interaction between microstructures and thermal or electrical properties is not clear for variously compositional alloys of the $\mathrm{Sn}-\mathrm{Zn}$ system as the two phase materials consisting of pure $\mathrm{Zn}$ and $\mathrm{Sn}$-solid solution containing $\mathrm{Zn}$ of less than 1 mass $\%$.

The present study aimed to measure the temperature dependence of the specific resistivity and thermal conductivity used in electrical and thermal calculations, and to investigate the interaction between microstructures and thermal or electrical properties, for $\mathrm{Sn}-\mathrm{Zn}$ system alloys with several different compositions as a candidate alloy system for lead-free fuse elements used in electric power line.

\section{Experimental Procedures}

Pure Sn with the purity of $99.9 \%$ and pure $\mathrm{Zn}$ with the purity of $99.9 \%$ were weighed according to the nominal compositions of some Sn-Zn alloys (Sn-0, 1, 9, 20, 50, 80, 100 mass\% Zn). They were melted in a graphite crucible in air. Molten metals were held for $1.2 \mathrm{ks}$ at temperatures which were $50 \mathrm{~K}$ higher than their liquidus temperatures. Their melts were poured into the cold split-die made of carbon steel in air. Figure 1 shows the cylindrical die which has the inner diameter of $15 \mathrm{~mm}$ and height of $116 \mathrm{~mm}$. 


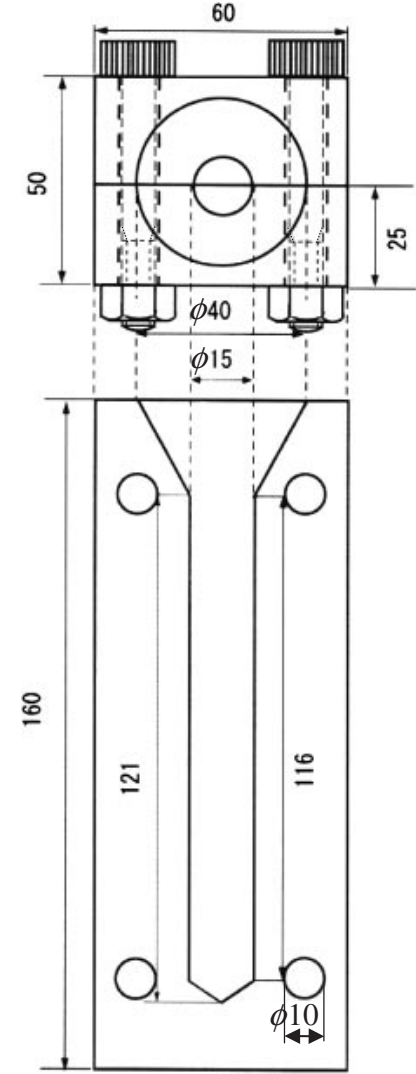

Fig. 1 Schematic drawing of the split-die made of carbon steel, used in this study. Units are given in $\mathrm{mm}$.

The microstructural observation was carried out using an optical microscope. The specific resisitivity $\left(\rho_{e}\right)$ was simultaneously measured from room temperature to about $470 \mathrm{~K}$ by the standard four probe d.c. method in air using a computer-controlled equipment. The size of samples was $1 \times 1 \times 17 \mathrm{~mm}$. The temperature gradient along the length $(17 \mathrm{~mm})$ of samples for the measurement of $\rho_{e}$ was about $5 \mathrm{~K}$. The thermal conductivity $(\lambda)$ was measured from $293 \mathrm{~K}$ to $460 \mathrm{~K}$ using samples with the diameter of $11 \mathrm{~mm}$ and length of $50 \mathrm{~mm}$, under the steady-state condition in air. Figure 2 shows the construction of a Sn-Zn sample, copper heating rod with a cartridge heater and cooling plate for measurement of the heat conduction. The value of $\lambda$ was obtained using the relation represented in eq. (1),

$$
\lambda \frac{\Delta T_{i}}{L_{i}} \frac{\pi D^{2}}{4}=E I
$$

where, the product of $E$ and $I$ represented the amount of Joule's heat discharged to a cartridge heater with a capability of $200 \mathrm{~V}$ and $200 \mathrm{~W}, D$ and $\Delta T_{i}$ represented the diameter of samples and the temperature difference caused between the points keeping a fixed length $\left(L_{i}\right)$ of $5 \mathrm{~mm}$, respectively. The temperature was measured by the $\mathrm{K}$ type thermocouples of the diameter of $0.1 \mathrm{~mm}$.

Density measurement using a high density liquid was performed by Archimedes' method. Differential thermal analysis (DTA) was carried out on some alloys. DTA measurement was conducted at a constant heating and cooling rates of $5 \mathrm{~K} / \mathrm{min}$ in a low purity argon stream.

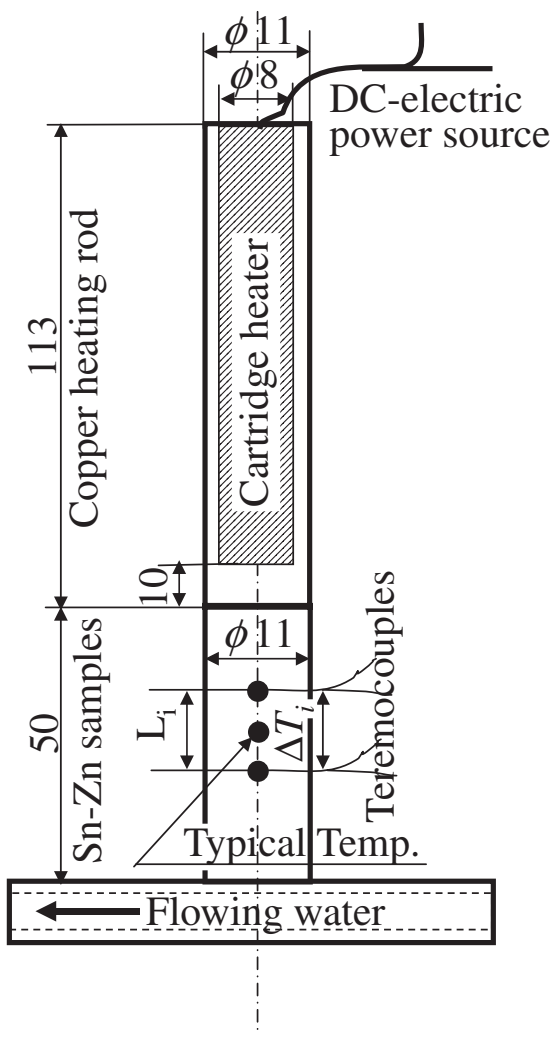

Fig. 2 The construction of a Sn-Zn sample, copper heating rod with a cartridge heater and cooling plate for measurement of the heat conduction under steady-state condition. Units are given in millimeters.

\section{Results and Discussion}

\subsection{Microstructures}

The microstructures of as-cast alloys (Sn-0, 1, 9, 20, 50, 80, 100Zn) are shown in Fig. 3. Pure Sn, Sn-1Zn and pure Zn samples showed pure $\mathrm{Sn}-$, Sn solid solution- and pure $\mathrm{Zn}$ monophases with the particle size of 72,127 or $40 \mu \mathrm{m}$, respectively, depending on their cooling rates. The microstructure of the Sn-9Zn alloy showed a typical Sn-Zn eutectic structure with the light contrast Sn-solid solution and the dark contrast $\mathrm{Zn}$ phases which were formed alternately. $\mathrm{Sn}-9 \mathrm{Zn}$ is considered to be a two phase material consisting of pure $\mathrm{Zn}$ and Sn-solid solution with $\mathrm{Zn}$ of less than 1 mass\%, and Snsolid solution phase was continuous one in this alloy. Sn20Zn showed a microstructure consisting of a plate-like primary $\mathrm{Zn}$ and eutectic consisting of Sn-solid solution and pure $\mathrm{Zn}$. The amount of the primary $\mathrm{Zn}$ phase increased and the amount of eutectic decreased as $\mathrm{Zn}$ contents increased in Sn-20, 50, 80Zn alloys, as shown in Fig. 2(d)-(f). The Sn-20, $50,80 \mathrm{Zn}$ alloys showed two grains consisting of the primary $\mathrm{Zn}$ and eutectic. The eutectic and primary $\mathrm{Zn}$ were continuously present throughout the microstructures of Sn-20Zn and $\mathrm{Sn}-80 \mathrm{Zn}$ alloys, respectively. In other words, the primary $\mathrm{Zn}$ and eutectic were considered to be second phases in eutectic and $\mathrm{Zn}$ matrixes for Sn-20Zn and Sn-80Zn alloys, respectively. In contrast, both the eutectic and primary $\mathrm{Zn}$ were continuously present in $\mathrm{Sn}-50 \mathrm{Zn}$ alloy.

\subsection{Specific resistivity}

The $\rho_{e}$ of some $\mathrm{Sn}-\mathrm{Zn}$ alloys (Sn-0, 1, 9, 20, 50, 80, 100Zn) 

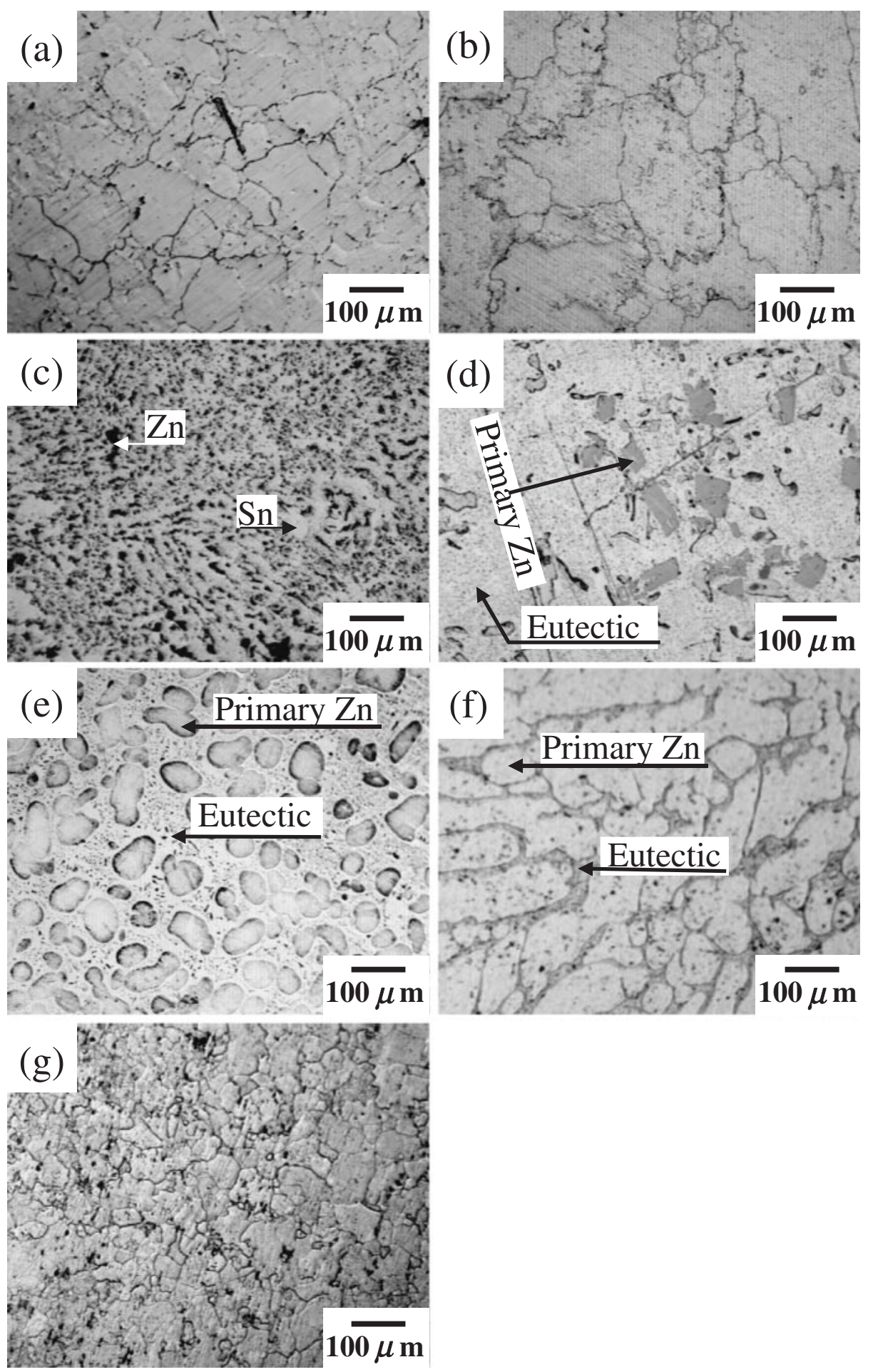

Fig. 3 The optical micrographs of as-cast materials for (a) pure Sn, (b) Sn-1Zn, (c) Sn-9Zn, (d) Sn-20Zn, (e) Sn-50Zn and (f) Sn-80Zn and (g) pure Zn.

was measured at various temperatures in the range of 293 $470 \mathrm{~K}$. Figure 4 shows the temperature and compositional dependence of the $\rho_{e}$. In this figure, 7 straight lines approximated by a least squares method using experimental values of $\rho_{e}$ for each composition mean only the qualitative tendency of its change. As can be seen in the figure, the $\rho_{e}$ increased monotonously with increasing temperature, regardless of $\mathrm{Zn}$ contents in alloys. The $\rho_{e}$ also increased even at same temperatures as the $\mathrm{Sn}$ content increased in alloys.
The temperature dependence of the $\rho_{e}$ increased as the Sn content increased in alloys. Below the eutectic point $(471 \mathrm{~K})$ for $\mathrm{Sn}-0$ to $100 \mathrm{Zn}$ alloys of the widely compositional range, the $\rho_{e}$ is roughly represented as the functions of the composition and temperature using eq. (2),

$\rho_{e}=(-0.0313 Z n+0.0549)$ Temp $+2.2011 Z n-3.3643$ (2)

where, $\mathrm{Zn}$ and Temp represent the mass fraction of $\mathrm{Zn}$ in alloys and temperature, respectively. 


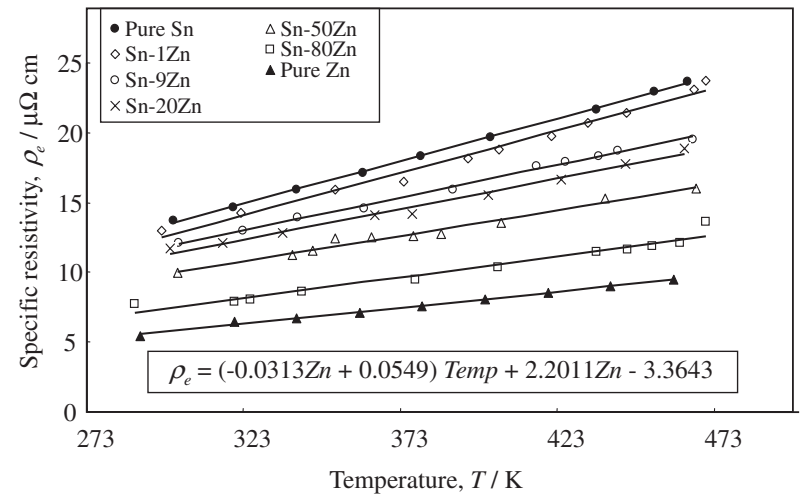

Fig. 4 Specific resistivity measured in this study for some $\mathrm{Sn}-\mathrm{Zn}$ alloys.

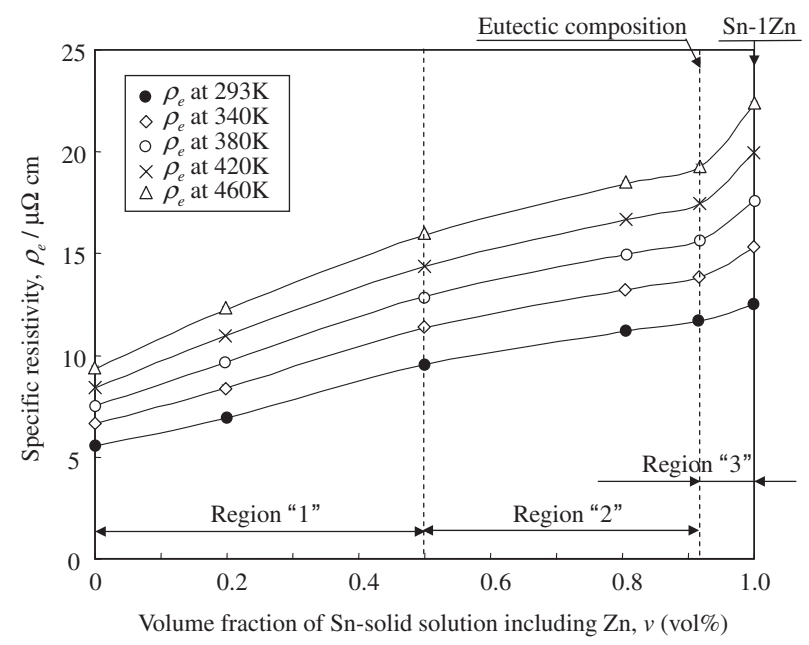

Fig. 5 Relation between specific resistivity and volume fraction of Snsolid solution at some temperatures for several $\mathrm{Sn}-\mathrm{Zn}$ alloys.

The $\rho_{e}$ in microstructures consisting of two phases depends on microstructural characteristics such as volume fraction and morphology of each phase. It is considered from Fig. 3 and the constitutional diagram ${ }^{14)}$ that $\mathrm{Sn}-\mathrm{Zn}$ system alloys are two phase materials consisting of the Sn-solid solution with $\mathrm{Zn}$ of less than 1 mass $\%$ and pure $\mathrm{Zn}$, in widely compositional range of $\mathrm{Sn}-\mathrm{Zn}$ system. There are different morphologies in $\mathrm{Zn}$ and $\mathrm{Sn}$-solid solution grains between the primary phase and eutectic depending on alloy compositions. Figure 5 shows relation between the experimental value of $\rho_{e}$ obtained from its straight line for each composition in Fig. 4 and volume fraction of Sn-solid solution at some temperatures. The values in volume fraction of Sn-solid solution were obtained from the density (Sn-solid solution: 7.30 $\mathrm{Mg} / \mathrm{m}^{3}, \mathrm{Zn}: 7.13 \mathrm{Mg} / \mathrm{m}^{3}$, described in detail in section 3.4 ) and amount ratio in the equilibrium diagram ${ }^{14}$ ) for $\mathrm{Sn}$-solid solution and $\mathrm{Zn}$. In this figure, the value of 1 in volume fraction of the Sn-solid solution corresponds to the composition of Sn-1Zn showing the solubility limit of $\mathrm{Zn}$ in the Snsolid solution. ${ }^{14)}$ The lines showing compositional dependence of $\rho_{e}$ can be classified into three regions (1,2 and 3). The composition showing the change in slopes of the lines corresponded to that showing the change in microstructural characteristics which meant the difference in the kinds and continuity for matrix and second phases consisting of primary Zn, Sn-solid solution or eutectic, as shown in Fig. 3. The $\rho_{e}$ depends on the microstructural characteristics mentioned above. The lines were approximated by eq. (3),

$$
\rho_{e}=a S n+b
$$

where, $S n$ and $a$ or $b$ represent the volume fraction of Sn-solid solution and constants, respectively. The values of $a$ and $b$ are listed in Table 1. Furthermore, $\rho_{e}$ in the narrowly compositional range of the region 1,2 and 3 can be exactly represented as the function of the composition and temperature using eqs. (4), (5) and (6), respectively, compared with eq. (2) which was roughly proposed in widely compositional range,

$$
\begin{aligned}
\rho_{e}= & (0.0304 S n+0.0236) \text { Temp } \\
& -0.8564 S n-1.4518 \\
\rho_{e}= & (0.0177 S n+0.0292) \text { Temp } \\
& -0.0295 S n-1.5555 \\
\rho_{e}= & (0.1611 S n-0.1024) \text { Temp } \\
& -37.2265 S n+32.5440
\end{aligned}
$$

Higher and lower values in $a$ and $b$, respectively at higher temperatures were shown in the region 3 showing compositions of higher Sn contents, because of strongly dependence in temperatures for $\rho_{e}$ of pure $\mathrm{Sn}$ as shown in Fig. 4. The values of $a$ and $b$ are mainly decided depending on values in $\rho_{e}$ of pure $\mathrm{Zn}$ and $\mathrm{Sn}$.

Figure 6 shows the relation between the experimental values of $\rho_{e}$ at 293 and $460 \mathrm{~K}$ which were obtained from the straight lines in Fig. 4 and the approximation using eqs. (4)(6) in the compositional range of Sn-1 to $100 \mathrm{Zn}$. The primary $\mathrm{Zn}$ and eutectic are continuous grains in region 1 and 2 shown

\begin{tabular}{|c|c|c|c|c|c|c|}
\hline \multirow{2}{*}{ Temperatures } & \multicolumn{2}{|c|}{ Region 1 (Sn-50 to $100 \mathrm{Zn})$} & \multicolumn{2}{|c|}{ Region 2 (Sn-9 to $50 \mathrm{Zn})$} & \multicolumn{2}{|c|}{ Region 3 (Sn-1 to 9Zn) } \\
\hline & $a$ & $b$ & $a$ & $b$ & $a$ & $b$ \\
\hline $293 \mathrm{~K}$ & 8.053 & 5.4718 & 5.1491 & 6.9915 & 9.9703 & 2.5403 \\
\hline $340 \mathrm{~K}$ & 9.4822 & 6.5824 & 5.9862 & 8.3609 & 17.542 & -2.2727 \\
\hline $380 \mathrm{~K}$ & 10.698 & 7.5276 & 6.6885 & 9.529 & 23.986 & -6.3689 \\
\hline $420 \mathrm{~K}$ & 11.915 & 8.4728 & 7.3963 & 10.696 & 30.431 & -10.465 \\
\hline $460 \mathrm{~K}$ & 13.131 & 9.418 & 8.104 & 11.862 & 36.875 & -14.561 \\
\hline
\end{tabular}
in Fig. 5, respectively. Fan, ${ }^{15)}$ Maxwell ${ }^{12}$ and Landauer ${ }^{13)}$ models can be represented using eqs. (7), (8) and (9), respectively. Their estimations were also shown in this figure, and their models were proposed for $\rho_{e}$ of composites with widely range in the volume fraction of second phases,

Table 1 The values of $a$ and $b$ in eq. (3) for approximation of slopes in three regions shown in Fig. 5. 


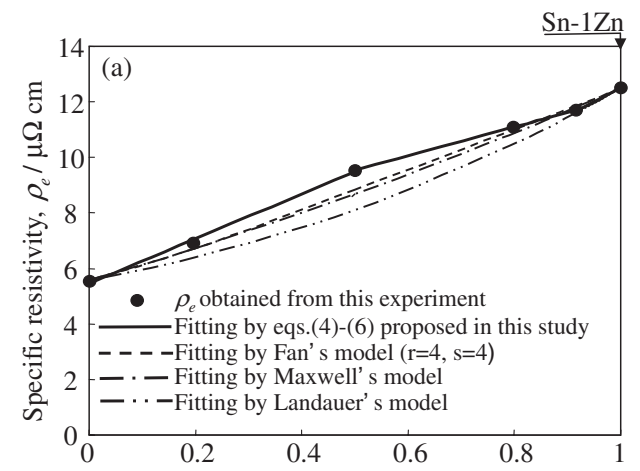

Volume fraction of Sn-solid solution including $\mathrm{Zn}, v$ (vol\%)

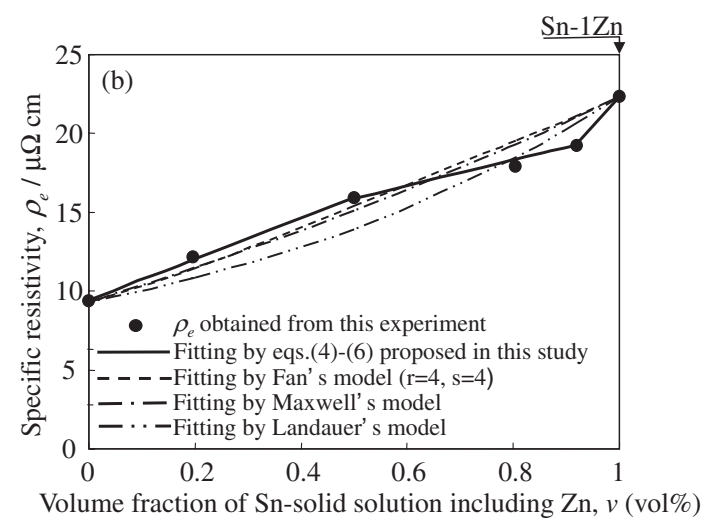

Fig. 6 Relation between the experimental values of specific resistivity at (a) 293 and (b) $460 \mathrm{~K}$ shown in Fig. 4 and the approximation using eqs. (4)-(6) in the compositional range of Sn-1 to 100Zn, and comparison of fitting data by eqs. (4)-(6) proposed in this study with those by Fan's, Maxwell's and Landauer's models.

$$
\begin{aligned}
\frac{1}{\rho_{e}}= & \frac{f_{m}^{r}}{\rho_{m}}+\frac{f_{2}^{s}}{\rho_{2}}+\frac{\left(1-f_{m}^{r}-f_{2}^{s}\right)^{2}}{\rho_{m}\left(f_{m}-f_{m}^{r}\right)+\rho_{2}\left(f_{2}-f_{2}^{s}\right)} \\
\rho_{e}= & \rho_{m}\left[\left\{2 \rho_{2}+\rho_{m}+f_{2}\left(\rho_{2}-\rho_{m}\right)\right\}\right. \\
& /\left\{2 \rho_{2}+\rho_{m}-2 f_{2}\left(\rho_{2}-\rho_{m}\right)\right] \\
\frac{1}{\rho_{e}}= & \frac{1}{4}\left\{\frac{1}{\rho_{m}}\left(3 f_{m}-1\right)+\frac{1}{\rho_{2}}\left(3 f_{2}-1\right)+\sqrt{D}\right\}
\end{aligned}
$$

where, $\rho_{m}$ and $\rho_{2}$ were the $\rho_{e}$ of a matrix (Sn-solid solution) and second phase (pure $\mathrm{Zn}$ ), respectively, $f_{m}$ and $f_{2}$ were volume fraction of matrix and second phases, respectively, $r$ and $s$ were constants meaning characteristics of the phase arrangement in the microstructure, $D$ was defined by eq. (10),

$$
D=\left\{\frac{1}{\rho_{m}}\left(3 f_{m}-1\right)+\frac{1}{\rho_{2}}\left(3 f_{2}-1\right)\right\}^{2}+8 \frac{1}{\rho_{m}} \frac{1}{\rho_{2}}
$$

The estimation results by Fan, Maxwell and Landauer models showed appreciable deviations from experimental results, because the difference in the morphologies could not be considered between the $\mathrm{Zn}$ or Sn-solid solution phase as a primary crystal and these phases crystallized by the eutectic reaction. In contrast, the approximation of $\rho_{e}$ using eqs. (4)(6) in the compositional classification (region 1-3) from the point of microstructural characteristics, is in good agreement with the experimental results, because not only volume fraction of $\mathrm{Zn}$ and Sn-solid solution phases but morphologies of these phases were considered by both use of these equations and application of three compositional ranges for

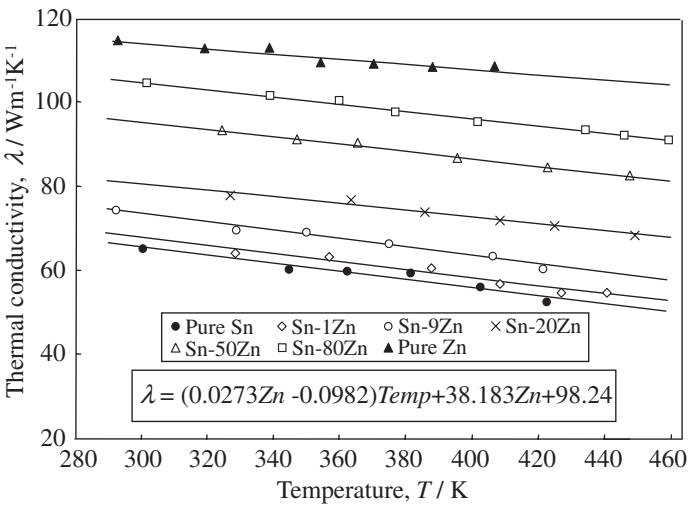

Fig. 7 Thermal conductivity measured in this study for some $\mathrm{Sn}-\mathrm{Zn}$ alloys.

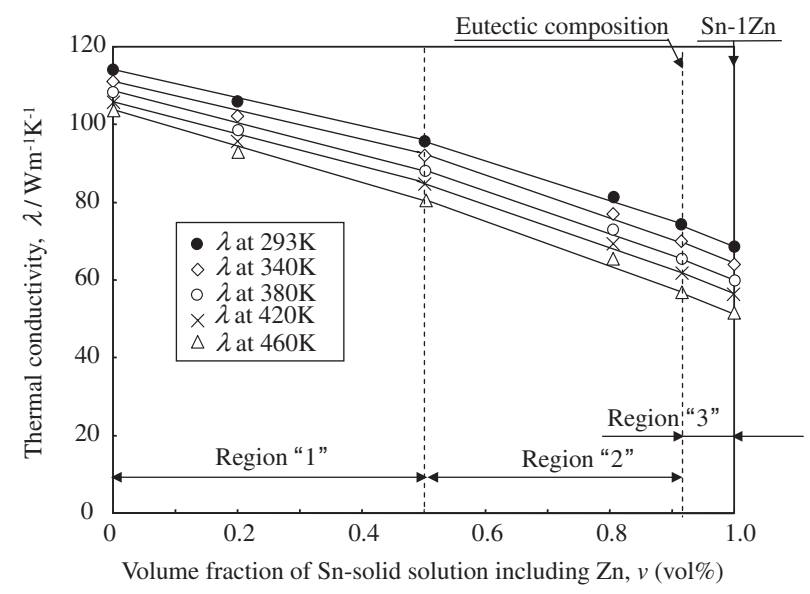

Fig. 8 Relation between thermal conductivity and volume fraction of Snsolid solution at some temperatures for several $\mathrm{Sn}-\mathrm{Zn}$ alloys.

the microstructural characteristics shown in Fig. 3. The $\rho_{e}$ of $\mathrm{Sn}-\mathrm{Zn}$ alloys can be exactly estimated by the procedure mentioned above, which leads to an exact estimation of temperature-distribution in lead-free fuse elements of electric power line, by electrical and thermal calculations on the basis of Ohm's and Fourier's laws.

\subsection{Thermal conductivity}

The $\lambda$ of some $\mathrm{Sn}-\mathrm{Zn}$ alloys (Sn-0, 1, 9, 20, 50, 80, 100Zn) were measured at some temperatures of the range of 293$460 \mathrm{~K}$. Figure 7 shows the temperature and compositional dependence of the $\lambda$, and the behavior of its change using 7 lines in the same manner with Fig. 4. As can be seen in this figure, the $\lambda$ decreased monotonously with increasing temperature, regardless of $\mathrm{Zn}$ contents in alloys. The $\lambda$ also decreased even at same temperatures as the Sn content increased in alloys. Below the eutectic point $(471 \mathrm{~K})$ for $\mathrm{Sn}-0$ to $100 \mathrm{Zn}$ alloys of the widely compositional range, the $\lambda$ is roughly represented as the functions of the composition and temperature using eq. (11),

$$
\lambda=(0.0273 Z n-0.0982) \text { Temp }+38.183 Z n+98.24
$$

Figure 8 shows relation between the experimental values of $\lambda$ and volume fraction of Sn-solid solution at some temperatures in the same manner with Fig. 5. In this figure, the value of 1 in volume fraction for the Sn-solid solution 
Table 2 The values of $a$ and $b$ in eq. (12) for approximation of slopes in three regions shown in Fig. 8.

\begin{tabular}{|c|c|c|c|c|c|c|}
\hline \multirow{2}{*}{ Temperatures } & \multicolumn{2}{|c|}{ Region 1 (Sn-50 to $100 \mathrm{Zn})$} & \multicolumn{2}{|c|}{ Region 2 (Sn-9 to $50 \mathrm{Zn})$} & \multicolumn{2}{|c|}{ Region 3 (Sn-1 to 9Zn) } \\
\hline & $a$ & $b$ & $a$ & $b$ & $a$ & $b$ \\
\hline $293 \mathrm{~K}$ & -35.344 & 113.25 & -50.799 & 121.61 & -75.101 & 143.5 \\
\hline $380 \mathrm{~K}$ & -40.631 & 107.78 & -52.401 & 114.86 & -69.045 & 129.04 \\
\hline $420 \mathrm{~K}$ & -41.551 & 104.66 & -53.21 & 111.86 & -67.833 & 123.93 \\
\hline $460 \mathrm{~K}$ & -44.549 & 102.36 & -53.882 & 108.73 & -65.411 & 117.61 \\
\hline
\end{tabular}

corresponds to the composition of $\mathrm{Sn}-1 \mathrm{Zn}$ showing the solubility limit of $\mathrm{Zn}$ in the Sn-solid solution. ${ }^{14)}$ The lines showing compositional dependence of $\lambda$, as well as $\rho$ shown in Fig. 5, can be also classified into three regions (1, 2 and 3). The composition showing the change in slopes of the lines corresponded to that showing the change in microstructural characteristics which meant the difference in the kinds and continuity for matrix and second phases consisting of primary Zn, Sn-solid solution or eutectic, as shown in Fig. 3. The $\lambda$ depends on the microstructural characteristics mentioned above. The lines were approximated by eq. (12),

$$
\lambda=a S n+b
$$

The values of $a$ and $b$ are listed in Table 2. Furthermore, $\lambda$ in the narrowly compositional range of the region 1,2 and 3 can be exactly represented as the function of the composition and temperature using eqs. (13), (14) and (15), respectively, compared with eq. (11) which was roughly proposed in widely compositional range,

$$
\begin{aligned}
\lambda= & (-0.0540 S n-0.0656) \text { Temp } \\
& -19.497 S n+132.46 \\
\lambda= & (-0.0186 S n-0.0770) \text { Temp } \\
& -45.335 S n+144.16 \\
\lambda= & (0.0585 S n-0.1554) \text { Temp } \\
& -92.180 \text { Sn }+188.95
\end{aligned}
$$

Lower and higher values in $a$ and $b$, respectively were shown in the region 3 showing compositions of higher Sn contents regardless of temperatrures, because of lower values of $\lambda$ in pure $\mathrm{Sn}$.

Figure 9 shows the relation between the experimental values of $\lambda$ at 293 and $460 \mathrm{~K}$ which were obtained from its straight line for each composition in Fig. 7 and the approximation using eqs. (13)-(15) in the compositional range of Sn-1 to $100 \mathrm{Zn}$. The primary $\mathrm{Zn}$ and eutectic are continuous grains in region 1 and 2 shown in Fig. 8, respectively. Estimations by Maxwell ${ }^{12)}$ and Landauer ${ }^{13)}$ models represented using eqs. (8) and (9), respectively, were also shown in this figure. Eqs. (8) and (9) were also used in the estimation of $\lambda$, by substituting $\lambda$ into $1 / \rho_{e}$. In eqs. (8) and (9), $\lambda_{m}$ and $\lambda_{2}$ were thermal conductivity of a matrix (Snsolid solution) and second phase (pure $\mathrm{Zn}$ ), respectively.

The estimation results by Maxwell and Landauer models showed appreciable deviations from experimental result. In contrast, the approximation of $\lambda$ using Eqs. (13)-(15) in the compositional classification (region 1-3) from the point of microstructural characteristics, is in good agreement with the experimental results, because not only volume fraction of $\mathrm{Zn}$

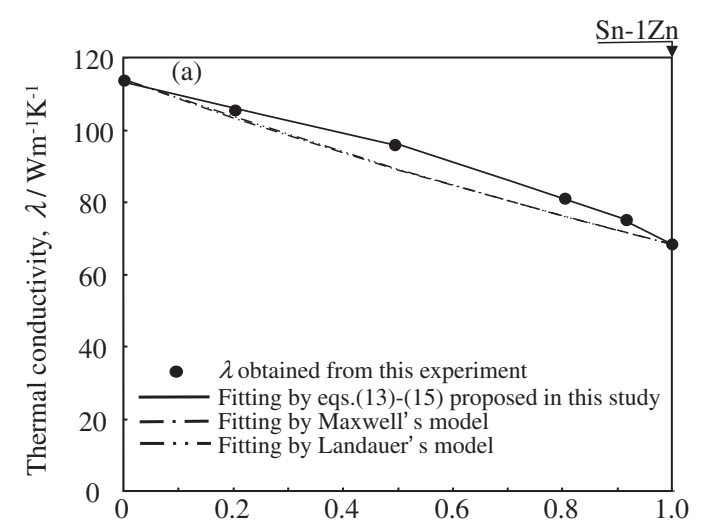

Volume fraction of Sn-solid solution including $\mathrm{Zn}, v$ (vol\%)

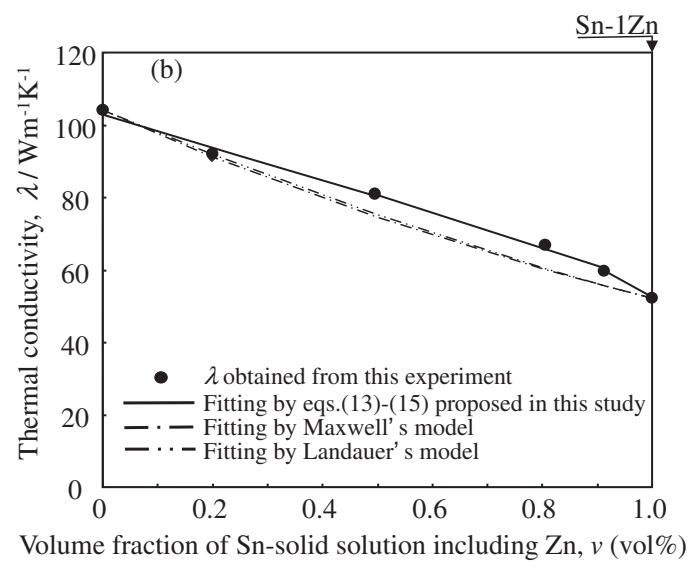

Fig. 9 Relation between the experimental values of thermal conductivity at (a) 293 and (b) $460 \mathrm{~K}$ shown in Fig. 7 and the approximation using eqs. (13)-(15) in the compositional range of $\mathrm{Sn}-1$ to $100 \mathrm{Zn}$, and comparison of fitting data by eqs. (13)-(15) proposed in this study with those by Maxwell's and Landauer's models.

and Sn-solid solution phases but morphologies of these phases were considered by both use of these equations and application of three compositional ranges for microstructural characteristics shown in Fig. 3. The $\lambda$ of $\mathrm{Sn}-\mathrm{Zn}$ alloys can be exactly estimated by the procedure mentioned above, which leads to an exact estimation of temperature-distribution in lead-free fuse elements of electric power line, by electrical and thermal calculations on the basis of Ohm's and Fourier's laws.

It is found that $\rho_{e}$ and $\lambda$ can be estimated with good accuracy by use of eqs. (4)-(6) and (13)-(15), respectively, in application of the compositional ranges classified from the standpoint of continuity or non-continuity of constituent phases such as the primary $\mathrm{Zn}, \mathrm{Sn}$-solid solution and eutectic in microstructures of $\mathrm{Sn}-1$ to $100 \mathrm{Zn}$ alloys. 
Table 3 Density measured according to Archimedes' principle.

\begin{tabular}{cc}
\hline Alloys & Density, $\mathrm{Mg} / \mathrm{m}^{3}$ \\
\hline Pure Sn & 7.31 \\
Sn-1Zn & 7.30 \\
Sn-9Zn & 7.29 \\
Sn-20Zn & 7.27 \\
Sn-50Zn & 7.23 \\
Sn-80Zn & 7.17 \\
Pure Zn & 7.13 \\
\hline
\end{tabular}

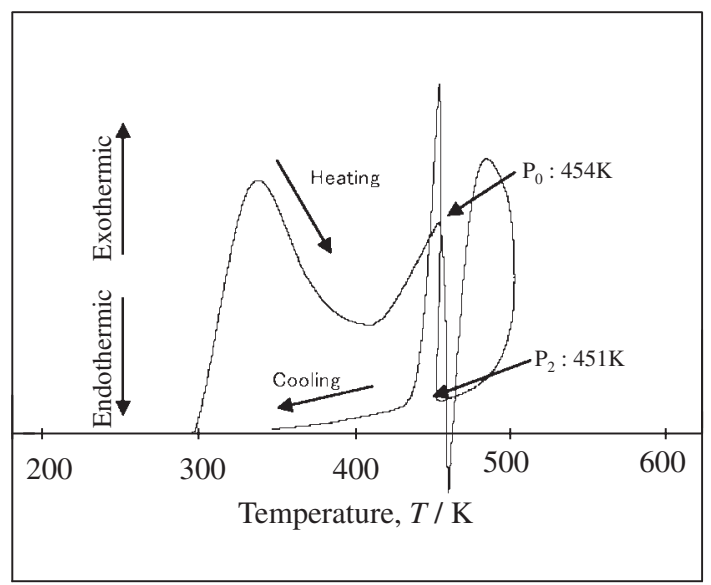

Fig. 10 DTA curves obtained from the practically used $\mathrm{Sn}-39 \mathrm{~Pb}-1.6 \mathrm{Ti}-$ $0.1 \mathrm{Cu}$ alloy.

\subsection{Other properties and comparisons with the practical alloy}

The densities of Sn-0, 9, 20, 50, 80, 100Zn alloys were measured at $293 \mathrm{~K}$ according to Archimedes' principle. Their values are listed in Table 3. The values of their densities were changed depending on the contents of the primay Sn-solid solution and $\mathrm{Zn}$ phases.

The $\mathrm{Sn}-39 \mathrm{~Pb}-1.6 \mathrm{Ti}-0.1 \mathrm{Cu}$ alloy has been used as an AClow voltage fuse element in electric power line. ${ }^{4)}$ The melting point of $\mathrm{Pb}$-free alloys should be comparable to that of practical used alloys. The determination of the melting point was carried out on the practical alloy, as seen in Fig. 10. In the DTA heating curves of the practical alloy, one endothermic peak $\left(P_{0}\right)$ appeared at $454 \mathrm{~K}$. Meanwhile, one peak $\left(P_{2}\right)$ appeared at $451 \mathrm{~K}$ in its cooling curve. $P_{0}$ or $P_{2}$ corresponded to the eutectic reaction.

DTA was also carried out using $\mathrm{Sn}-\mathrm{Zn}$ alloys in order to compare with the result obtained from $\mathrm{Sn}-39 \mathrm{~Pb}-1.6 \mathrm{Ti}-0.1 \mathrm{Cu}$. Figure 11 shows DTA curves obtained from the $\mathrm{Sn}-9 \mathrm{Zn}$ and Sn-80Zn alloys, as typical examples. In the DTA heating curves of Sn-9Zn and $\mathrm{Sn}-80 \mathrm{Zn}$, one endothermic peak $\left(P_{0}\right)$ appeared at 474 and $471 \mathrm{~K}$, respectively. Meanwhile, in the cooling curve of $\mathrm{Sn}-80 \mathrm{Zn}$, two exothermic peaks $\left(P_{1}\right.$ and $\left.P_{2}\right)$ appeared at 649 and $470 \mathrm{~K}$, respectively, and in that of Sn$9 \mathrm{Zn}$, one peak $\left(P_{2}\right)$ appeared at $471 \mathrm{~K} . P_{0}$ or $P_{2}$ and $P_{1}$ corresponded to the eutectic reaction and the crystallization of primary $\mathrm{Zn}$ phase, respectively. The amount of primary $\mathrm{Zn}$ phase increased as the temperature decreased in the range of temperature of 649 to $470 \mathrm{~K}$ in the cooling process for the $\mathrm{Sn}$ $80 \mathrm{Zn}$ alloy. In other words, both liquid caused by the eutectic
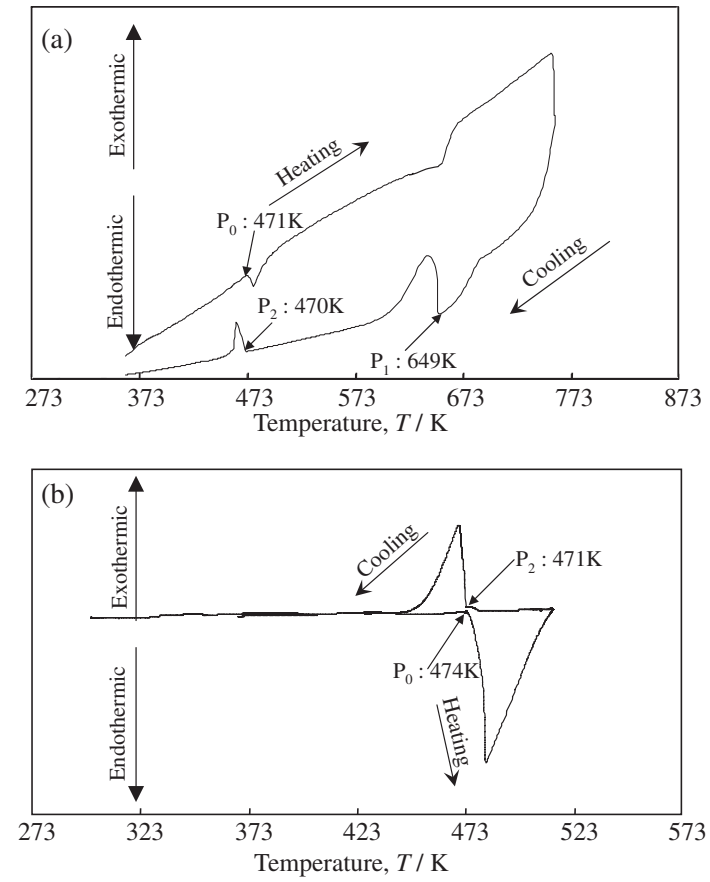

Fig. 11 DTA curves obtained from (a) Sn-80Zn and (d) Sn-9Zn alloys.

reaction and $\mathrm{Zn}$-solid were present in this temperature range of heating process. In the range between the liquidus and eutectic temperatures, the presence of the solid and liquid lead to satisfy the property of un-melt down under the higher fixed value (210A) of electric current as one of main requirements for fuse elements, ${ }^{3,4)}$ compared with the $\mathrm{Sn}-9 \mathrm{Zn}$ and $\mathrm{Sn}-39 \mathrm{~Pb}-1.6 \mathrm{Ti}-0.1 \mathrm{Cu}$ alloys of eutectic compositions. Furthermore, the value in volume fraction of $\mathrm{Zn}$-solid in this temperature range has to be optimized experimentally for satisfying both melt and un-melt down under the fixed values of 99A and 210A, respectively. ${ }^{3,4)}$ The reaction temperatures are listed in Table 4 for several Sn-Zn alloys.

The same behavior of DTA was observed for the $\mathrm{Sn}-39 \mathrm{~Pb}-$ 1.6Ti-0.1Cu and Sn-9Zn alloys, as shown in Figs. 10 and 11(b). Temperature in the eutectic reaction of $\mathrm{Sn}-\mathrm{Zn}$ system alloys was approximately $20 \mathrm{~K}$ higher than that of the Sn$39 \mathrm{~Pb}-1.6 \mathrm{Ti}-0.1 \mathrm{Cu}$ alloy, as listed in Table 4. Therefore, it is roughly considered that the $\mathrm{Sn}-\mathrm{Zn}$ system alloys satisfy the requirement of melting point for an alternative fusible alloy, except for wettability on copper.

The $\rho_{e}, \lambda$ and specific heat $\left(c_{p}\right)$ measured at room temperature are listed in Table 5, for the Sn-9Zn, Sn-39Pb-1.6Ti$0.1 \mathrm{Cu}^{4)}$ alloys and pure copper ${ }^{4)}$ for electric power line. Their values of $\mathrm{Sn}-9 \mathrm{Zn}$ in $\mathrm{Sn}-\mathrm{Zn}$ system alloys are listed as a typical example. The $c_{p}$ was measured on a sample with the diameter of $9 \mathrm{~mm}$ and thickness of $1.7 \mathrm{~mm}$, by the laser flash method. ${ }^{7)}$ Temperature conductivity was obtained using values of the $\lambda, c_{p}$ and density. The value of the temperature conductivity for $\mathrm{Sn}-9 \mathrm{Zn}$ is 1.41 times larger than that of the $\mathrm{Sn}-39 \mathrm{~Pb}-1.6 \mathrm{Ti}-0.1 \mathrm{Cu}$ alloys, which approaches to that of pure copper and leads to the larger amount of the heat transfer by heat conduction. In contrast, the value of $\rho_{e}$ of Sn-9Zn alloy is 0.78 times, compared with that of the practical alloy, which means lower amount of the heat generation in the proposed alloy. 
Table 4 Reaction temperatures obtained from DTA curves of the several Sn-Zn alloys and the practical alloy as a reference.

\begin{tabular}{lcc}
\hline \multicolumn{1}{c}{ Alloys } & Heating process & \multicolumn{2}{c}{ Cooling process } \\
\cline { 2 - 3 } & $\mathrm{P}_{0}$ (Eutectic Temp.), K & $\mathrm{P}_{1}$ (Liquidus Temp.), K \\
\hline Sn-9Zn & 474 & 556 \\
Sn-20Zn & 474 & 626 \\
Sn-50Zn & 472 & 649 \\
Sn-80Zn & 471 & 471 \\
Sn-39Pb-1.6Ti-0.1Cu & 454 & 470 \\
\hline
\end{tabular}

Table 5 The specific resistivity, thermal conductivity, specific heat and temperature conductivity at room temperature of Sn-9Zn, Sn$39 \mathrm{~Pb}-1.6 \mathrm{Ti}-0.1 \mathrm{Cu}$ alloys and pure copper.

\begin{tabular}{lccc}
\hline \multicolumn{1}{c}{ Alloys } & $\begin{array}{c}\text { Specific Resistivity, } \\
\mu \Omega \mathrm{cm}\end{array}$ & $\begin{array}{c}\text { Thermal conductivity, } \\
\mathrm{W} / \mathrm{m} / \mathrm{K}\end{array}$ & $\begin{array}{c}\text { Specific heat, } \\
\mathrm{kJ} / \mathrm{kg} / \mathrm{K}\end{array}$ \\
\hline $\mathrm{Sn}-9 \mathrm{Zn}$ & 12.1 & 75.3 & 0.226 \\
$\mathrm{Sn}-39 \mathrm{~Pb}-1.6 \mathrm{Ti}-0.1 \mathrm{Cu}$ & 15.6 & 52.0 & 0.196 \\
$\mathrm{Pure} \mathrm{Cu}$ & 1.6 & 394.0 & 0.385 \\
\hline
\end{tabular}

Fuse elements are optimized by design of shape and alloycomposition. Size and composition of fuse elements can be proposed using eqs. (4)-(6) and (13)-(15) of $\rho_{e}$ and $\lambda$ represented as a function of composition and temperature in the compositional classification (region 1-3) from the point of microstructural characteristics, by computer simulation consists of electrical and thermal calculations on the basis of Ohm's and Fourier's laws.

\section{Conclusinos}

(1) Sn-Zn alloys showed two phase microstructures consisting of Sn-solid solution and pure $\mathrm{Zn}$ phases. The eutectic, primary $\mathrm{Zn}$ or $\mathrm{Sn}$-solid solution was present as a continuous grain depending on compositions of $\mathrm{Sn}-\mathrm{Zn}$ alloys. Sn-Zn alloys could be classified into three microstructural groups (Sn-50 to $100 \mathrm{Zn}, \mathrm{Sn}-9$ to $50 \mathrm{Zn}$ and Sn-1 to $9 \mathrm{Zn}$ ) depending on the difference in the kinds and continuity for matrix and second phases consisting of the primary Zn, Sn-solid solution or eutectic.

(2) Specific resistivity increased as temperatures and Sn contents increased in Sn-Zn alloys. In contrast, thermal conductivity decreased as temperature and Sn contents increased in Sn-Zn alloys. Specific resistivity and thermal conductivity were estimated using equations representing by a function of the alloy composition and temperature.

(3) Specific resistivity and thermal conductivity could be estimated with good accuracy by use of proposed equations as a function of temperature and composition in the compositional ranges classified from the standpoint of continuity or non-continuity of constituent phases such as primary $\mathrm{Zn}$, Sn-solid solution and eutectic phases in microstructures of $\mathrm{Sn}-1$ to $100 \mathrm{Zn}$ alloys. In the proposed estimations, not only volume fraction of $\mathrm{Zn}$ and Sn-solid solution phases but morphologies of these phases were considered in SnZn alloys.

(4) Temperature in the eutectic reaction of $\mathrm{Sn}-\mathrm{Zn}$ alloys was approximately $20 \mathrm{~K}$ higher than that of the practically used Sn-39Pb-1.6Ti-0.1Cu alloy. The presence of the solid of $\mathrm{Zn}$ or $\mathrm{Sn}$ solid solution and liquid above the eutectic temperature, leads to satisfy the property of unmelt down under the higher fixed value (210A) of electric current as one of main requirements for fuse elements, compared with the Sn-9Zn alloy showing the eutectic composition.

\section{REFERENCES}

1) S. Jin, D. R. Frear and J. W. Morris, Jr.: J. Electron Mater. 23 (1994) 709-713.

2) K. Suganuma: Solid State Mater. Sci. 5 (2001) 55-64.

3) T. Narahashi: Thesis for Master Degree, Hiroshima University, Higashi-Hiroshima, Japan, (2006) pp. 2-5.

4) O. Yanagisawa, K. Matsugi, Y. Kikuchi, M. Sako, T. Narahashi, K. Fujii, Y. Kumagai and K. Fujita: Sn alloys for electric fuse elements and electric fuses using their elements, Japan Patent, (2006) opening 2006-161130.

5) Electronic Material Handbook: ed. by ASM International, vol. 1, (ASM International, Materials Park, Ohio, 1989) pp. 965-966.

6) P. Biocca: Surf. Mount Technol. 13 (1999) 64-67.

7) K. Matsugi, G. Sasaki, O. Yanagisawa, Y. Kumagai and K. Fujii: Mater. Trans. 47 (2006) 2413-2420.

8) W. Yang and R. W. Messler Jr.,: J. Electron Mater. 23 (1994) 765-772.

9) H. Mavoori, J. Chin, S. Vaynman, B. Moran, L. Keer and ME. Fine: J. Electron Mater. 26 (1997) 783-790.

10) F. Vnuk, M. Sahoo, D. Baragar and R. W. Smith: J. Mater. Sci. 15 (1980) 2573-2583.

11) R. Elliott and A. Moore: Scripta Metall. 3 (1969) 249-251.

12) J. C. Maxwell: A Treatise on Electricity and Magnetism, vol. 1, (Oxford Univ. Press, Oxford, 1873) p 365.

13) R. Landauer: J. Appl. Phys. 23 (1952) 779-784.

14) M. Hansen: Constitution of Binary Alloys (McGraw-Hill Book Company, Inc., New York, 1958) pp. 1217-1219.

15) Z. Fan: Acta Metall. Mater. 43 (1995) 43-49. 